Chingmuh Lee MD, Wing-Fai Kwan MD, Shen-Kou Tsai MD PhD, Büng-Jaw Chen MD, Marlyn Cheng MD

\title{
A clinical assessment of desflurane anaesthesia and comparison with isoflurane
}

In 48 randomly assigned ASA I adult patients undergoing elective orthopaedic procedures, we compared the pharmacodynamics of desflurane (DF) and isoflurane (IF), and their pharmacokinetics during rapid induction of deep anaesthesia (via face mask, to 1.5-2 MAC, afier thiopentone), maintenance of anaesthesia at 1.25 MAC, and emergence therefrom. During induction, laryngeal reactions ranging from mild crowing to laryngospasm occurred more frequently with $D F$ than with IF $(15 / 24 D F, 5 / 24 I F ; P<0.05)$ and was more severe (9) $24 D F, 1 / 24 I F$, excluding the mildest form, $P<0.05$ ). As a result, induction of anaesthesia was not accomplished faster with $D F$, in spite of a faster equilibration between exhaled and inhaled concentrations. Emergence from $D F$ was more rapid and less complicated by delirium. Pharmacokinetically, the exhaled concentration of DF reached $90 \%$ of the inhaled concentration within five minutes of induction, whereas that of IF lagged behind and remained $25 \%$ below the inhaled concentration ( 1 vs $1.34 \pm 0.05$ ) even one hour after induction. Premature ventricular contractions did not occur in any patient even during periods of difficulty with the airway and oxygen desaturation. It is concluded that DF is a safe anaesthetic, pharmacokinetically superior to IF but clinically inferior for induction of anaesthesia via a face mask. Because of the fast equilibration, the exhaled concentration of $D F$ can be controlled more precisely by the dial setting of the vaporiser.

\section{Key words}

ANAESTHETICS, VOLATILE: desflurane, isoflurane.

From the Department of Anesthesiology, Harbor-UCLA

Medical Center, Torrance, CA.

Supported in part by Anaquest, Inc.

Part of the results presented at the 1990 Annual Meeting of the American Society of Anesthesiologists

Address correspondence to: Dr. Chingmuh Lee, Department of Anesthesiology, Harbor-UCLA Medical Center, 1000 West Carson Street, Torrance, CA 90509, USA. Accepted for publication 22nd February, 1993.
Quarante-huit adultes ASA I soumis à une chirurgie orthopédique programmée ont été aléatoirement choisis pour comparer la pharmacodynamique du desflurane (DF) en de lisoflurane (IF), et leur pharmacocinétique au cours de linduction rapide d'une anesthésie profonde (par un masque facial, à 1,5-2 $M A C$, après thiopental), au cours de l'entretien de l'anesthésie à 1,25 MAC, et ensuite au cours du réveil. Pendant linduction, des réactions laryngées allant du léger stridor au laryngospasme se sont manifestées plus fréquemment avec $D F$ qu'avec IF (15/ $24 D F, 5 / 24 I F, P<0,05)$. Linduction de lanesthésie n'a pas été réalisée plus vite avec $D F$, malgré l'équilibration plus rapide entre les concentrations expirées et inspirées. Le réveil après DF a été plus rapide et a présenté moins de confusion. Pharmacocinétiquement, la concentration expirée du DF a atteint $90 \%$ de la concentration inspirée dans les cinq minutes de l'induction, tandis que celle de l'IF est restée plus stationnaire et s'est maintenue à $25 \%$ sous la concentration inspirée (1 versus 1,34 土0,05) même heure après línduction. Aucune extrasystole ventriculaire ne s'est produite chez les patients, même pendant des épisodes difficiles de maintien de l'airway et de désaturation artérielle. On en conclut que DF et un agent anesthésique sûr, pharmacocinétiquement supérieur à l'IF mais cliniquement inférieur pour linduction de lanesthésie par un masque facial. Grâce à une équilibration rapide, la concentration expirée de DF peut-être contrôlée plus précisément par l'ajustement du contrôle du vaporisateur.

Desflurane (DF), $\mathrm{CH}_{3}-\mathrm{CHF}-\mathrm{O}-\mathrm{CHF}_{2}$, a new inhalational anaesthetic, differs from isoflurane (IF), $\mathrm{CF}_{3}-\mathrm{CHCl}-\mathrm{O}$ $\mathrm{CHF}_{2}$, by fluorine substitution of the alpha-ethyl chlorine. A blood/gas partition coefficient of 0.42 , less than that of nitrous oxide $\left(\mathrm{N}_{2} \mathrm{O}\right)$, suggests rapid equilibration and emergence. $^{1-4}$ Like IF, DF causes vasodilatation and compensatory tachycardia. ${ }^{5-7}$ Fluorine substitution of the chlorine atom increases the vapour pressure, which along with a relatively low oil/gas partition coefficient (18.7) suggests that DF will have a greater MAC value than those of currently available inhalational vapour anaesthetics. ${ }^{8-10}$

In a separate Phase II-III clinical study of the neuromuscular effects of DF and its interaction with atracurium, we had to establish a deep level of DF anaes- 
TABLE I Demographics of patients and duration of DF or IF anaesthesia

\begin{tabular}{lllll}
\hline & Age $(y r)$ & $W t(\mathrm{~kg})$ & $\operatorname{Sex}(M / F)$ & Duration (min) \\
\hline $\mathrm{DF}$ & & & & \\
$n=24$ & $29.3 \pm 1.5$ & $75.6 \pm 1.5$ & $24 / 0$ & $70-284(141 \pm 10)$ \\
$\mathrm{IF}$ & & & & \\
$n=24$ & $31.4 \pm 1.8$ & $74.3 \pm 2.2$ & $23 / 1$ & $60-272(121 \pm 9)$ \\
$P$ & $\mathrm{NS}$ & $\mathrm{NS}$ & $\mathrm{NS}$ & $\mathrm{NS}$ \\
\hline
\end{tabular}

thesia, insert endotracheal tubes, and establish a steady level of 1.25 MAC anaesthesia before administration of neuromuscular relaxants. It was desirable to accomplish these expeditiously. We also had to restore complete neuromuscular transmission prior to the termination of anaesthesia. This provided us with an unique opportunity to assess, in some of these patients, (1) the induction characteristics of DF in adults in a hypothetical situation requiring rapid establishment of deep anaesthesia via a face mask, (2) the equilibration between exhaled and inhaled concentrations of DF during induction, maintenance and emergence of anaesthesia, and (3) the emergence characteristics of DF after maintenance of surgical anaesthesia at 1.25 MAC. For the patient group of young healthy adults, the MAC of DF was assumed to be $7.25 \%$ (vs $1.28 \%$ IF) based on earlier observations. ${ }^{8-10}$

\section{Methods}

With approval of our Human Subjects Committee, 48 patients (47 male, 1 female), 18-48-yr-old, ASA Class I, and undergoing elective orthopaedic surgery of the limb (Table I) were informed and consented to the study. Premedication was not given, except that all patients received midazolam 1-4 mg titrated $i v$ for mild sedation in doses of $1 \mathrm{mg}$ in the holding area and on the surgical table before induction of anaesthesia. All monitors were noninvasive and included arterial blood pressure (BP), heart rate (HR), ECG (lead II), core temperature, pulse oximetry and end-expiratory $\mathrm{CO}_{2}$. The end-expiratory $\mathrm{CO}_{2}$, the concentrations of $\mathrm{O}_{2}$ and $\mathrm{N}_{2} \mathrm{O}$ in the breathing circuit, and the breath-by-breath high/low ("inhaled"/ "exhaled") concentrations of DF or IF were monitored at the $Y$ juncture of the breathing circuit by a Datex ${ }^{\circledR}$ monitor calibrated prior to each use. Patients were pre-assigned to DF or IF group by a randomization table. All anaesthetic inductions, management, and efforts to awaken the patient at the end of surgery were done in a standardized manner by the same anaesthetist (CL), assisted by the same team of observers.

While the patient was breathing oxygen, thiopentone $4-5 \mathrm{mg} \cdot \mathrm{kg}^{-1}$ was given $i v$ to induce sleep. Nitrous oxide up to $67 \%$ (inspired) was added to the circle system. Des- flurane up to $15 \%$ or IF up to $3.5 \%$ (at the vaporizer) was introduced in an escalating manner. The total fresh gas input was adjusted from $6-8 \mathrm{~L} \cdot \mathrm{min}^{-1}$ initially to 3-5 $\mathrm{L} \cdot \mathrm{min}^{-1}$ after 3-5 min. Ventilation was spontaneous or assisted, with an aim to establish deep anaesthesia rapidly for intubation of the trachea. Thiopentone 2 $\mathrm{mg} \cdot \mathrm{kg}^{-1}$ was added $i v$ two minutes after the initial dose to the latter half of patients in an attempt to ease the induction. All events including breath-holding, salivation, hiccough, coughing, laryngospasm, sighing, and limb movement were observed. These were timed and recorded by a full-time observer. On clinical judgment that deep anaesthesia had been established, usually signaled by virtual cessation of spontaneous breathing at 1.5-2 MAC, a few controlled breaths were delivered manually and laryngoscopy was performed. Nitrous oxide had been withdrawn and its residual exhaled concentration reduced to $\leq 20 \%$ in preparation for laryngoscopy. When laryngospasm occurred, $\mathrm{N}_{2} \mathrm{O}$ was withdrawn earlier. On first laryngoscopy, $4 \mathrm{ml}$ lidocaine $4 \%$ were sprayed into the trachea and onto the larynx. The tension of the jaw and the reaction to the spray were observed. The mask was reapplied and once the reactions to the spray subsided, laryngoscopy was repeated and the tracheal tube was inserted. Nitrous oxide was not used again. Use of neuromuscular blocking relaxant was limited to atracurium given after surgical incision, and the block was reversed prior to attempts to awaken the patients. The inhaled and exhaled concentrations of the anaesthetic were recorded every minute during induction.

Laryngeal reactions during induction of anaesthesia were graded by the following scale:

0 No reaction.

1 Slight laryngeal crowing, positive airway pressure required to ventilate the lungs increased by $<10 \mathrm{~cm} \mathrm{H}_{2} \mathrm{O}$, no $\mathrm{O}_{2}$ desaturation on pulse oximetry.

2 Between scales 1 and 3, with laryngeal crowing, cough, and increased airway pressure required to ventilate the lungs, but ventilation was not completely interrupted at any time and pulse oximetry decreased by $<3 \%$.

3 Forceful cough and/or impossibility to ventilate the lungs for up to $20 \mathrm{sec}$, with $\mathrm{O}_{2}$ desaturation; but $\mathrm{O}_{2}$ saturation remained $>90 \%$.

4 Complete laryngeal closure and impossible to ventilate the lungs for more than $20 \mathrm{sec}$ and/or a decrease of pulse oximetry to $<90 \%$ saturation; but improvement in ventilation occurred before pulse oximetry decreased to $85 \%$ saturation. No cyanosis. No neuromuscular blocking relaxants required to resolve the laryngeal reaction.

5 Pulse oximetry reached $\leq 85 \%$ saturation and worsening. This called for immediate termination of the study, treatment with neuromuscular blocking relaxant or any 
appropriate measure, and official recognition as a failed induction due to an adverse event.

Other occurrences such as salivation, urination, cardiac dysrhythmia, seizure, sweating, or mottling of the skin were also monitored.

Upon intubation of the trachea, the anaesthetic regimen was adjusted to the following: DF $9 \%$ or IF $1.6 \%$ exhaled (both $1.25 \mathrm{MAC}$ ), fresh $\mathrm{O}_{2}$ inflow $3 \mathrm{~L} \cdot \mathrm{min}^{-1}$, no $\mathrm{N}_{2} \mathrm{O}$, core temperatures $35-37.5^{\circ} \mathrm{C}$, measured nasopharyngeally or oesophageally, and controlled ventilation for exhaled $\mathrm{CO}_{2}$ of $31-35 \mathrm{mmHg}$. Supplemental anaesthesia was limited to fentanyl $0.05 \mathrm{mg}$ given $i v$ more than 30 min before the end of surgery in the latter half of the study. Intraoperatively, the inhaled and exhaled concentrations of DF or IF were recorded every $30 \mathrm{~min}$. Intravenous fluid was lactated Ringer's solution, the first litre of which also contained $5 \%$ glucose. Patients were placed on a warming mattress during the entire course.

Towards the end of surgery, the oropharynx was suctioned, and the expired $\mathrm{CO}_{2}$ tension was allowed to increase to $40-45 \mathrm{mmHg}$ by controlled hypoventilation. Then the anaesthetic was terminated abruptly. Fresh $\mathrm{O}_{2}$ inflow was set at $8 \mathrm{~L} \cdot \mathrm{min}^{-1}$ and ventilation was set at $10 \mathrm{ml} \cdot \mathrm{kg}^{-1}, 9-10 \mathrm{bpm}$ for five minutes. The concentration of exhaled DF or IF was read every minute until the tracheal tube was removed. The patient was observed and tested minute by minute for the following: pupil size, spontaneous coughing, spontaneous body motion unrelated to coughing, and reactions to two loud calls at the ear with a gentle shaking of the shoulder, and a threesecond manual pinch to the shoulder, in that order. All patients were tested in the same manner by the principal investigator. After the fifth minute, mechanical ventilation was discontinued, manual ventilation was initiated, and spontaneous breathing was allowed. The trachea was not suctioned, as it was not required in any patient. To permit assessment of awakening and return of reflexes under standardised conditions, the oropharynx was not suctioned again until the time of tracheal extubation, which was noted.

Throughout the awakening process, during the transportation to, and while in the post-anaesthesia care unit (PACU), the patient was observed for return of mental function. Orientation to name, age, and body parts (left vs right, toe vs finger, mouth vs eyes) was determined. Nausea, vomiting, delirium, or shivering, if any, was noted. Shivering was graded as follows:

0 No shivering.

1 Mild shivering, intermittent and not simultaneously involving all four limbs.

2 Moderate shivering (between grades 1 and 3).

3 Marked shivering of all four limbs continuously for $\geq 30 \mathrm{sec}$.
TABLE II Induction of anaesthesia with DF or IF via face mask (with $\mathrm{N}_{2} \mathrm{O}$ and following sleep does of thiopentone)

\begin{tabular}{llll}
\hline & $\begin{array}{l}\text { Time to } \\
\text { 1.5 MAC } \\
(\text { min })\end{array}$ & $\begin{array}{l}\text { Time to } \\
\text { tracheal spray } \\
(\text { min })\end{array}$ & $\begin{array}{l}\text { Time to } \\
\text { tracheal intubation } \\
(\text { min })\end{array}$ \\
\hline DF & $6.9 \pm 0.6$ & $12.0 \pm 0.5$ & $14.3 \pm 0.7$ \\
IF & $5.5 \pm 0.4$ & $10.0 \pm 0.4$ & $12.8 \pm 0.6$ \\
$P$ & $(0.07)$ & $<0.05$ & 0.12 \\
\hline
\end{tabular}

Delirium was graded as follows:

0 No delirium.

1 Any vocalisation or non-reflex movement in a confused state, however mild.

2 Moderate delirium (between grades 1 and 3).

3 Loud phonation or forceful body motion requiring immediate nursing intervention.

Except otherwise indicated, all data are presented as mean \pm SEM and/or range. All comparisons were made by unpaired Student's t or chi square test for statistical significance level of $P<0.05$. The $P$ values between 0.05 and 0.2 are given for reference. Two patients in each group became transiently hypothermic $\left(34-35^{\circ} \mathrm{C}\right)$ and their data thereafter were excluded. The hypothermia resulted from rapid hydration, to treat arterial hypotension without reducing the inhaled anaesthetic.

\section{Results}

Demographic data of the DF and IF patients were similar (Table I). Addition of $2 \mathrm{mg} \cdot \mathrm{kg}^{-1}$ thiopentone during induction $0.05 \mathrm{mg}$ fentanyl during maintenance in the latter half of the study did not result in differences in any of the results.

\section{Induction}

An exhaled concentration of 1.5 MAC (10.8\%) was established with DF $6.9 \pm 0.6 \mathrm{~min}$ after its introduction. The trachea was sprayed with lidocaine at $12.0 \pm 0.5$ min and intubated at $14.3 \pm 0.7 \mathrm{~min}$. These latter values included the time taken to withdraw $\mathrm{N}_{2} \mathrm{O}$. Desflurane and IF groups (Table II) did not differ in the speed of induction to $1.5 \mathrm{MAC}$. The trachea was sprayed later in the DF than in the IF group, which was contrary to predictions.

Desflurane caused more laryngeal reactions than did IF (Table III), and the reactions were more severe (Table IV). In the four most severe cases $(D F=3$, IF $=1$ ), laryngeal closure occurred suddenly. During the laryngospasm, some patients required two anaesthetists to maintain some ventilation of the lungs and the laryngospasm did not abate until pulse oximetry had registered considerable desaturation, to $85-90 \%$. However, all cases 
TABLE III Airway reactions (cough and laryngospasm) during mask inhalational induction of anaesthesia with DF $(n=24)$ or IF $(n=24)$ following thiopentone

\begin{tabular}{|c|c|c|c|c|c|c|}
\hline & \multirow[b]{2}{*}{ Incidence } & \multicolumn{2}{|l|}{ Onset } & \multicolumn{2}{|l|}{ Resolution } & \multirow[b]{2}{*}{ Duration } \\
\hline & & Time (min) & Anaesth (\%) & Time (min) & Anaesth (\%) & \\
\hline DF & $15 / 24$ & $\begin{array}{l}4.6 \\
\pm 0.3\end{array}$ & $\begin{array}{l}8.3 \\
\pm 0.6\end{array}$ & $\begin{array}{l}10.1 \\
\pm 0.7\end{array}$ & $\begin{array}{l}11.3 \\
\pm 0.5\end{array}$ & $5.4 \pm 0.7$ \\
\hline IF & $5 / 24$ & $\begin{array}{l}3.0 \\
\pm 0.7\end{array}$ & $\begin{array}{l}0.8 \\
\pm 0.2\end{array}$ & $\begin{array}{l}6.4 \\
\pm 1.8\end{array}$ & $\begin{array}{l}1.6 \\
\pm 0.2\end{array}$ & $3.4 \pm 1.0$ \\
\hline$P$ & $<0.05$ & - & - & - & - & 0.19 \\
\hline
\end{tabular}

Notes: (1) Timed from the introduction of DF or IF (2) Anaesth (\%) refers to the exhaled concentration. (3) The onset, resolution and duration statistics are based on the actual incidence, i.e., $n=15$ (DF) or $n=5$ (IF).

TABLE IV Severity of laryngeal reaction encountered during DF or IF induction of anaesthesia under mask following thiopentone

\begin{tabular}{lcccccc}
\hline Severity & 0 & 1 & 2 & 3 & 4 & 5 \\
\hline DF $n=24$ & 9 & 6 & 4 & 2 & 3 & 0 \\
IF $n=24$ & 19 & 4 & 0 & 0 & 1 & 0 \\
\cline { 5 - 6 }$P$ & $<0.05$ & & \multicolumn{3}{c}{$<0.05$} & \\
\hline
\end{tabular}

of laryngospasm were resolved without the use of muscle relaxants and without cyanosis or any other complication. The laryngospasm was precipitated by manual compression of the breathing bag or an increase in the anaesthetic delivery in some but not all cases. It occurred at 8.3 $\pm 0.6 \%$ exhaled concentration of DF (Table III). Resolution of laryngospasm invariably followed deepening of anaesthesia with DF or IF and began as a gradual improvement in ventilation which was accompanied by a changing pitch of the crowing sound on successive breaths. Once completely resolved, the manual control of ventilation became effortless, and the required airway pressure was less than $10 \mathrm{mmHg}$. Laryngoscopy followed after a few more breaths. On intubation of the trachea, the end-expiratory $\mathrm{CO}_{2}$ was $44.2 \pm 1.4 \mathrm{mmHg}$ (DF) and $36.8 \pm 1.6 \mathrm{mmHg}$ (IF), respectively, $P<0.05$. There was no wheezing suggestive of bronchospasm in any case. Airway difficulty was not attributable to obstruction at the oropharynx, nor was it associated with secretion, regurgitation, vomiting or aspiration. During induction, spontaneous respiration diminished in spite of normal or above-normal end-expiratory $\mathrm{CO}_{2}$, so that the depth of anaesthesia we desired for laryngoscopy could not be established rapidly without assisted ventilation.

Hiccough occurred in nine patients (DF $=5, \mathrm{IF}=$ 4) immediately following the induction of sleep with thiopentone, the introduction of the inhalational anaesthetic, or the initiation of manual ventilation. It did not interfere with ventilation or induction and subsided on deepening anaesthesia before the first laryngoscopy. It did not coin- cide with laryngospasm. Gastrointestinal reactions were limited to a slight increase in salivation in patients with airway obstruction. There was no sweating, skin flushing, seizure, or skin mottling. Truncal and limb rigidity or motion occurred only in association with coughing and laryngospasm.

\section{Laryngoscopy}

At the first laryngoscopy all patients had very relaxed jaws and the spray was accomplished on the first attempt (Table V). The airway and cardiovascular reactions to laryngoscopy and spraying were self-limited and similar between DF and IF groups. The endotracheal tube was inserted without difficulty. A stylet was not required.

\section{Surgical incision and maintenance of anaesthesia}

At concentrations of $9.22 \pm 0.20 \%$ DF or $1.64 \pm 0.02 \%$ IF, no patient moved on surgical incision. The cardiovascular reactions to incision were mild and somewhat more noticeable with IF (Table VI). Maintenance of anaesthesia at 1.25 MAC was uneventful except that nodal rhythm was noted in two DF patients and in one IF patient. The nodal rhythm was intermittent and required no treatment. Respiratory effort was not observed in any patient at any time during surgery. As there was a tendency to gradual hypothermia, a warming blanket was used routinely. Fever did not occur. The 1.25 MAC exhaled anaesthetic concentration was maintained throughout the case uneventfully.

\section{Haemodynamics, cardiac rhythmicity, and autonomic reactions}

Cardiac dysrhythmia, besides nodal rhythm, did not occur in any patient, even during airway obstruction, hypercarbia, and oxygen desaturation. Any hypertension was associated with airway difficulties. After induction, there was a tendency to hypotension with compensatory tachycardia. At a steady 1.25 MAC anaesthesia, mean arterial BP decreased by $11 \pm 4 \%$ (DF) vs $10 \pm 4 \%$ 
TABLE V Patients' response to the laryngoscopic spraying of local anaesthetic into the trachea under DF or IF anaesthesia

\begin{tabular}{|c|c|c|c|c|c|c|c|c|}
\hline & \multirow{2}{*}{$\begin{array}{l}\text { Anaesth conc } \\
(\text { exh }) \\
(\%)\end{array}$} & \multicolumn{2}{|c|}{ Before spray } & \multicolumn{2}{|l|}{ After spray* } & \multicolumn{3}{|c|}{ Airway reaction $\dagger$} \\
\hline & & $\begin{array}{l}B P \\
(m m H g)\end{array}$ & $\begin{array}{l}H R \\
\left(\min ^{-1}\right)\end{array}$ & $\begin{array}{l}\triangle B P \\
(\%)\end{array}$ & $\begin{array}{l}\Delta H R \\
(\%)\end{array}$ & $\begin{array}{l}0 \\
(/ 24)\end{array}$ & $\begin{array}{l}+ \\
(/ 24)\end{array}$ & $\begin{array}{l}++ \\
\text { (/24) }\end{array}$ \\
\hline \multirow[t]{2}{*}{$\mathrm{DF}$} & 12.8 & 80 & 109 & & & & & \\
\hline & \pm 0.5 & \pm 4 & \pm 5 & $+(7.2 \pm 3)$ & $+(6 \pm 2)$ & 7 & 12 & 5 \\
\hline \multirow[t]{2}{*}{ IF } & 2.3 & 85 & 107 & & & & & \\
\hline & \pm 0.2 & \pm 3 & \pm 4 & $+(15 \pm 5)$ & $+(9 \pm 3)$ & 7 & 8 & 9 \\
\hline$P(\mathrm{DF}$ vs IF) & - & NS & NS & 0.18 & NS & NS & & \\
\hline
\end{tabular}

*Higher value of the 1 st or 2 nd minute post-spray reading.

$\dagger$ Incidence $(n / 24)$ shown by grade of reaction: $0=$ no reaction, or barely reacted; $+=$ coughed, but no complete laryngeal closure; $++=$ transient laryngeal closure completely prevented the delivery of one breath or more.

TABLE VI Patients' response to surgical incision during DF or IF anaesthesia

\begin{tabular}{|c|c|c|c|c|c|}
\hline & \multirow{2}{*}{$\begin{array}{l}\text { Anaesth conc } \\
\text { (exh) } \\
(\%)\end{array}$} & \multicolumn{2}{|l|}{ Before } & \multicolumn{2}{|l|}{ After* } \\
\hline & & $\begin{array}{l}B P \\
(m m H g)\end{array}$ & $\begin{array}{l}H R \\
\left(\mathrm{~min}^{-1}\right)\end{array}$ & $\begin{array}{l}\triangle B P \\
(\%)\end{array}$ & $\begin{array}{l}\Delta H R \\
(\%)\end{array}$ \\
\hline \multirow[t]{2}{*}{ DF } & 9.22 & 75 & 97 & +7 & +5 \\
\hline & \pm 0.20 & \pm 4 & \pm 4 & \pm 4 & \pm 4 \\
\hline \multirow[t]{2}{*}{ IF } & 1.64 & 79 & 98 & 20 & 9 \\
\hline & \pm 0.02 & \pm 3 & \pm 4 & \pm 4 & \pm 3 \\
\hline$P$ (DF vs IF) & - & NS & NS & $<0.05$ & NS \\
\hline
\end{tabular}

*Third minute after incision.

TABLE VII Arterial BP and HR prior to, during, and after mask inhalational induction of DF or IF anaesthesia following thiopentone

\begin{tabular}{|c|c|c|c|c|c|c|c|c|}
\hline & \multirow{2}{*}{\multicolumn{2}{|c|}{ Before induction }} & \multicolumn{4}{|c|}{ During induction } & & \\
\hline & & & \multicolumn{2}{|c|}{ Highest BP } & \multicolumn{2}{|l|}{ Lowest BP } & \multicolumn{2}{|c|}{ After induction* } \\
\hline & $\begin{array}{l}\overline{B P} \\
(m m H g)\end{array}$ & $\begin{array}{l}H R \\
\left(\min ^{-1}\right)\end{array}$ & $\begin{array}{l}\Delta \overline{B P} \\
(\%)\end{array}$ & $\begin{array}{l}\Delta H R \\
(\%)\end{array}$ & $\begin{array}{l}\Delta \overline{B P} \\
(\%)\end{array}$ & $\begin{array}{l}\Delta H R \\
(\%)\end{array}$ & $\begin{array}{l}\Delta \overline{B P} \\
(\%)\end{array}$ & $\begin{array}{l}\Delta H R \\
(\%)\end{array}$ \\
\hline DF & $85 \pm 2$ & $78 \pm 3$ & $+(33 \pm 5)$ & $+(54 \pm 6)$ & $-(30 \pm 3)$ & $+(24 \pm 5)$ & $-(11 \pm 4)$ & $+(26 \pm 5)$ \\
\hline IF & $89 \pm 2$ & $76 \pm 3$ & $+(19 \pm 4)$ & $+(54 \pm 9)$ & $-(31 \pm 4)$ & $+(23 \pm 7)$ & $-(10 \pm 4)$ & $+(33 \pm 6)$ \\
\hline$P(\mathrm{DF}$ vs IF $)$ & NS & NS & $<0.05$ & NS & NS & NS & NS & NS \\
\hline
\end{tabular}

*At 1.25 MAC prior to incision.

(IF), and HR increased by $26 \pm 5 \%$ (DF) vs $33 \pm 6 \%$ (IF), NS (Table VII). Total fluid administered was 2.3 $\pm 0.1 \mathrm{~L}(\mathrm{DF})$ and $2.4 \pm 0.2 \mathrm{~L}(\mathrm{IF})$, respectively, NS.

\section{Emergence}

Emergence from DF anaesthesia was faster and smoother than from IF anaesthesia. The DF group of patients typically began breathing, reacted to the tracheal tube, opened eyes, and demonstrated mental function in a rapid sequence, with little delirium, agitation, salivation or swallowing (Tables VIII-X). No patients had any airway difficulty during emergence. Desflurane patients received an analgesic in the PACU earlier (first dose $39 \pm 4 \mathrm{~min}$ after discontinuation of DF vs $54 \pm 4 \mathrm{~min}$ after IF, $P$ $<0.05$ ). Patients stayed in the PACU for $95 \pm 9 \mathrm{~min}$ (DF) vs $92 \pm 4 \mathrm{~min}$ (IF), NS. All patients were discharged from the study without complications. There was no tracheal reintubation, unexpected admission, or changes in laboratory test results attributable to DF or IF.

\section{Pharmacokinetics of induction, maintenance, and emergence}

Figure 1 shows the minute-by-minute increase of the exhaled concentrations of DF and IF during induction. Fig- 
TABLE VIII Emergence from anaesthesia - return of reflex functions (min. from discontinuation of DF or IF)

\begin{tabular}{lllll}
\hline & Pupi & Cough & Pain $\dagger$ & Extubation \\
\hline DF & $3.2 \pm 0.3$ & $7.4 \pm 0.7$ & $7.8 \pm 0.6$ & $11.1 \pm 0.6$ \\
IF & $5.5 \pm 0.7$ & $7.6 \pm 1.7$ & $8.6 \pm 1.2$ & $15.6 \pm 1.0$ \\
$P($ DF vs IF $)$ & $<0.05$ & NS & NS & $<0.05$ \\
\hline
\end{tabular}

*From discontinuation of DF or IF to an increase in pupil size by $1.5 \mathrm{~mm}$.

$\dagger$ Reaction to a three-second painful manual pinch on the shoulder.

TABLE IX Emergence from DF or IF anaesthesia - return of mental functions (min)

\begin{tabular}{lclll}
\hline & & & \multicolumn{2}{l}{ Orientation (age, name, body) } \\
\cline { 4 - 5 } & Motion* & Awake $\dagger$ & lst & Last or all 3 \\
\hline DF & $7.5 \pm 0.9$ & $11.6 \pm 0.6$ & $15.2 \pm 0.6$ & $15.5 \pm 0.7$ \\
IF & $10.1 \pm 1.2$ & $18.8 \pm 1.8$ & $26.2 \pm 1.8$ & $28.2 \pm 2.3$ \\
$P($ DF vs IF $)$ & 0.08 & $<0.05$ & $<0.05$ & $<0.05$ \\
\hline
\end{tabular}

*Excluding movement associated with airway reflexes.

$\dagger$ Any correct response to verbal command or opening eyes spontaneously.

TABLE X Emergence from DF or IF anaesthesia - delirium, shivering, nausea and vomiting

\begin{tabular}{|c|c|c|c|c|c|c|c|c|c|}
\hline & \multicolumn{4}{|c|}{ Delirium } & \multicolumn{4}{|c|}{ Shivering } & \multirow{2}{*}{$\begin{array}{l}\text { Nausea and } \\
\text { vomiting }\end{array}$} \\
\hline & 0 & + & ++ & +++ & 0 & + & ++ & +++ & \\
\hline $\mathrm{DF}$ & 21 & 3 & 0 & 0 & 15 & 7 & 2 & 0 & 1 \\
\hline IF & 6 & 9 & 7 & 2 & 16 & 3 & 4 & 1 & 1 \\
\hline$P(\mathrm{DF}$ vs IF $)$ & \multicolumn{4}{|c|}{$<0.05$} & \multicolumn{4}{|c|}{ NS } & NS \\
\hline
\end{tabular}

ure 2 shows the corresponding exhaled/inhaled concentration ratios. Although the exhaled MAC value of DF did not rise faster, it equilibrated with its inhaled concentration faster than did IF. The exhaled/inhaled concentration ratios of DF at the 30th, 45th, and 60th $\mathrm{min}$ of administration (at 1.25 MAC exhaled) were $1.08 \pm$ $0.03,1.07 \pm 0.02$, and $1.07 \pm 0.02$ vs $1.42 \pm 0.02,1.40$ \pm 0.02 , and $1.34 \pm 0.05$ (IF), respectively, $P<0.05$, signifying a nearly complete equilibration of $\mathrm{DF}$, versus a $25-40 \%$ gradient for IF. On termination of the administration of the anaesthetics, DF was eliminated faster and more completely than was IF (Figure 3).

\section{Discussion}

Other than strict randomisation and identical treatment of DF and IF groups, this study is basically a clinical observation. Nevertheless, our data verify previous investigative reports on various aspects of DF pharmacology. First, our results are compatible with the protocol assumption that DF $7.25 \%$ and IF $1.28 \%$ were approximately equipotent, both being 1 MAC for young healthy adults. $^{8-10}$ The trachea was sprayed at $12.8 \% \mathrm{DF}$ and
$2.3 \% \mathrm{IF}$, respectively. Coincidently, these are 1.8 MAC for both anaesthetics. At this level, the jaw was relaxed, and 17 of 24 patients in each group reacted to the spray. The surgical incision was made at $9.22 \%$ DF and $1.64 \%$ IF, respectively. These would have been 1.27 MAC and $1.28 \mathrm{MAC}$, respectively. No patients moved on incision. Desflurane and IF patients also reacted similarly in the cardiovascular system, except for a tendency for the DF patients to be less reactive to the laryngoscopy and to surgical incision. This difference suggests that DF might have a lower "MAC BAR," i.e., a lower multiple of MAC required to block adrenergic response to surgical stress. ${ }^{11}$ The larger swing of arterial BP during the induction of DF anaesthesia might be attributable to the more severe airway obstruction. It is remarkable that ventricular premature beats did not occur even in the presence of laryngospasm, $\mathrm{O}_{2}$ desaturation, hypercarbia and cardiovascular excitement. The respiratory depressant effect of DF manifests as diminution or cessation of spontaneous breathing during induction. This clinical observation echoes the previously reported respiratory depressant effect of DF reported by Lockhart et al. ${ }^{12}$ and suggests 


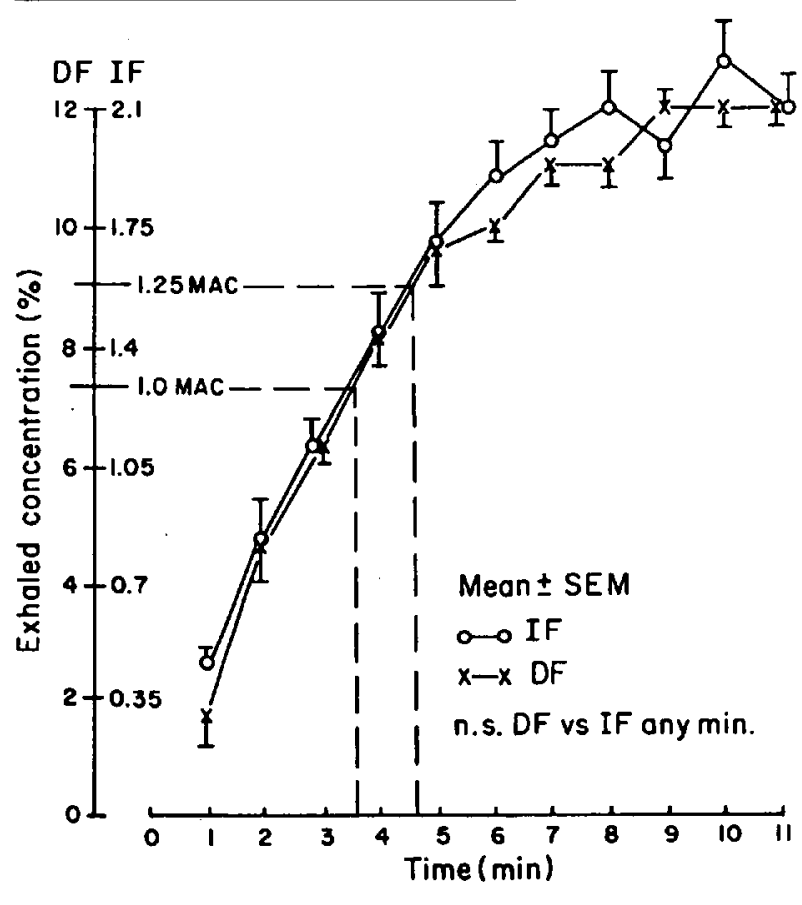

FIGURE 1 Rising exhaled concentration of DF or IF during induction of deep anaesthesia, administered with $\mathrm{N}_{2} \mathrm{O}$ via mask following $i v$ induction of unconsciousness with thiopentone.

that ventilation should be assisted if timely establishment of a deep anaesthesia with DF by mask is intended.

The higher incidence and the greater severity of laryngeal reaction to mask induction, as well as the failure to induce deep anaesthesia by mask more rapidly with DF than with IF, are contrary to expectations. As a matter of fact, induction was accomplished later with DF than with IF (Table II), and DF patients had higher endtidal $\mathrm{PCO}_{2}$ on intubation of the trachea. The difference did not seem to decrease with experience towards the latter part of the study. Since DF equilibrated between exhaled and inhaled concentrations faster, we attribute the failure to achieve a faster induction solely to the greater difficulty in delivering the anaesthetic to the alveoli. Such difficulty might be partly due to its pungency. We smelled DF ourselves and unanimously agreed that it was pungent, but less so than IF when smelled directly out of the bottle. However, it should be pointed out that even if DF is somewhat less pungent at the bottle, where it has three times the vapour pressure of IF $(664 \mathrm{mmHg}$ DF vs $240 \mathrm{mmHg}$ IF, at $20^{\circ} \mathrm{C}$ ), it may be more irritating at the concentration required for anaesthesia, at five to six times the concentration of IF. Our incidence of airway reaction with DF is similar to that observed by Rampil et al. ${ }^{10}$ However, the latter study did not include a direct

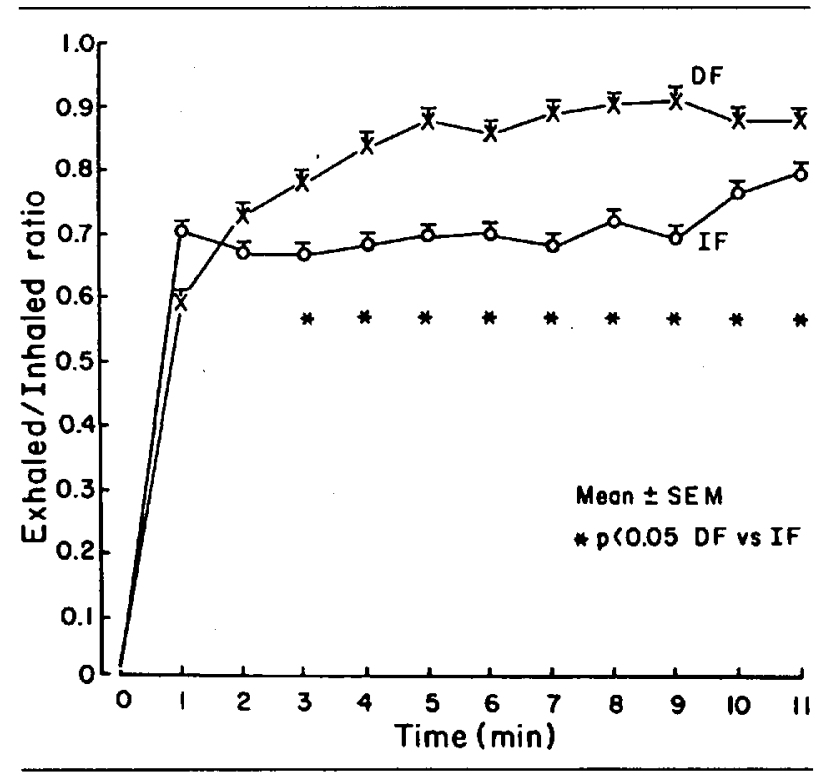

FIGURE 2 Equilibration between exhaled and inhaled concentrations of DF or IF during mask inductin of deep anaesthesia, administered along with $\mathrm{N}_{2} \mathrm{O}$ via mask following $\dot{w}$ induction of unconciousness with thiopentone.

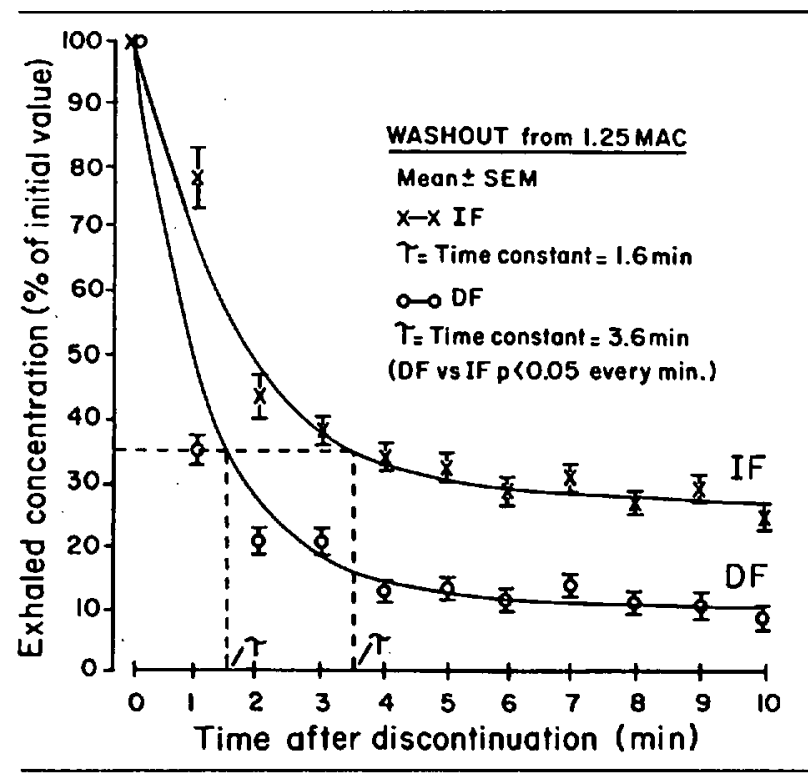

FIGURE 3 Decay of the exhaled concentration of DF or IF on discontinuation of the administration of the anaesthetic.

comparison with IF, and they encountered mainly cough and secretion rather than laryngospasm.

The difficulty with mask induction of DF anaesthesia must be put in proper perspective. Our study was planned before difficulty with mask induction of DF anaesthesia was publicized. We used no narcotics in premedication, recruited young male adults, most of whom were nonEnglish speaking, quite apprehensive and athletic, pushed 
for speedy induction of deep anaesthesia via the face mask with an anaesthetic and a vaporiser with which we had no previous experience, and used no neuromuscular blocking relaxants during induction. These factors probably predisposed our patients in both groups to laryngospasm. Avoidance of these factors may improve the induction characteristics but probably will not change the relative desirability of DF and IF as induction agents. Once the airway is secured, the problems we encountered are bypassed.

Theoretically, an anaesthetic with low blood/gas partition coefficient should be an excellent choice in situations where rapid induction via face mask is indicated. With rapid equilibration between exhaled and inhaled concentrations, less over-pressure is required, and chances of airway irritation and risk of overdosage are reduced. Our results suggest, on the contrary, that DF should be avoided in these situations.

The speed of action of DF manifests itself mainly during emergence from anaesthesia. The exhaled concentration decreased faster and patients awoke more rapidly with less delirium to earlier orientation to name, age, and body parts. Reducing the anaesthetic concentration towards the end of surgery, as well as the use of $\mathrm{N}_{2} \mathrm{O}$ to reduce DF requirement, will further speed up recovery. ${ }^{13}$ Early recovery from anaesthesia should reduce the level and duration of nursing care required in the PACU. Our DF and IF patients stayed in the PACU for the same time mainly because of protocol and policy requirements. The finding that in the PACU DF patients required an analgesic earlier and with a higher incidence probably reflects their rapid transition to clear sensorium.

Finally, $60 \mathrm{~min}$ after the beginning of induction, IF reached only two-thirds of equilibration between exhaled and inhaled concentrations. By contrast, DF reached $90 \%$ of such equilibration within five minutes. With this advantage, the alveolar concentration of DF can be controlled precisely and the anaesthesia depth can be manipulated quickly by the dial setting of the vaporiser at any time.

In conclusion, DF is a safe inhalational anaesthetic, superior in pharmacokinetics but clinically inferior to IF as an induction agent when administered via a face mask.

\section{References}

1 Eger EI II. Partition coefficients of $\mathrm{I}-653$ in human blood, saline, and olive oil. Anesth Analg 1987; 66: 971-3.

2 Eger EI II, Johnson BH. Rates of awakening from anesthesia with I-653, halothane, isoflurane, and sevoflurane: a test of the effect of anesthetic concentration and duration in rats. Anesth Analg 1987; 66: 977-82.

3 Yasuda N, Lockhart SH, Eger EI II, et al. Kinetics and desflurane, isoflurane, and halothane in humans. Anesthesiology 1991; 74: 489-98.

4 Smiley R, Ornstein E, Matteo RS, Pantuck EJ, Pantuck $C B$. Desflurane and isoflurane in surgical patients: comparison of emergence time. Anesthesiology 1991; 74: 425-8.

5 Jones RM, Cashman JN, Mant TGK. Clinical impressions and cardiorespiratory effects of a new fluorinated inhalation anaesthetic, desflurane (I-653), in volunteers. $\mathrm{Br} \mathbf{J}$ Anaesth 1990; 64: 11-5.

6 Cahalan MK, Weiskopf RB, Eger EI II, et al. Hemodynamic effects of desflurane/nitrous oxide anesthesia in volunteers. Anesth Analg 1991; 73: 147-64.

7 Weiskofi RB, Cahalan MG, Ionescu P, et al. Candiovascular actions of desflurane with and without nitrous oxide during spontaneous ventilation in humans. Anesth Analg 1991; 73: 165-74.

8 Eger EI II. Anesthetic potency and lipid solubility (Letter). Anesth Analg 1990; 70: 117-9.

9 Jones RM, Cashman JN, Eger EI II, Damask MC, Johnson $B H$. Kinetics and potency of desflurane (I-653) in volunteers. Anesth Analg 1990; 70: 3-7.

10 Rampil IJ, Lockhart SH, Zwass MS, et al. Clinical characteristics of desflurane in surgical patients: minimal alveolar concentration. Anesthesiology 1991; 74: 429-33.

11 Roizen MF, Horrigan RW, Frazer BM. Anesthetic doses blocking adrenergic (stress) and cardiovascular responses to incision - MAC BAR. Anesthesiology 1981; 54: 390-8.

12 Lockhart SH, Rampil IJ, Yasuda N, Eger EI II, Weiskopf $R B$. Depression of ventilation by desflurane in humans. Anesthesiology 1991; 74: 484-8.

13 Ghouri $A F$, Bodner $M$, White $P F$. Recovery profile after desflurane-nitrous oxide versus isoflurane-nitrous oxide in outpatients. Anesthesiology 1991; 74: 419-24. 